\title{
Sugar Futures as an Investment Alternative During Market Turmoil: Case Study of 2008 and 2020 Market Drop
}

\author{
Julia Babirath $^{1} \cdot$ Karel Malec $^{2} \cdot$ Rainer Schmitl $^{1} \cdot$ Jeta Sahatqija $^{2}$ • \\ Mansoor Maitah $^{2}$ (D) Sylvie Kobzev Kotásková ${ }^{2} \cdot$ Kamil Maitah $^{2}$
}

Received: 8 May 2020/Accepted: 24 September 2020/Published online: 16 October 2020

(c) Society for Sugar Research \& Promotion 2020

\begin{abstract}
In times of turbulent financial markets, investors all around the globe seek for opportunities protecting their portfolios from devastating losses. Historically, commodities were regarded as a safe haven providing sound returns which offset potential losses arising from dropping equity prices in times of market turmoil. While sugar would have provided a proper hedge against crashing equity markets during the initiation of the 2007 bear market and the onset financial crisis, sugar prices dropped likewise equity during the outbreak of COVID-19 and the consequent market shock. The goal of the paper is to elaborate on the differences in sugar price dynamics during the aforementioned economic disruptions by employing a multiple linear regression approach using data from the last quarter 2007 as well as the first quarter of 2019. The findings suggest
\end{abstract}

Mansoor Maitah

maitah@pef.czu.cz

Julia Babirath

1819001101@fh-burgenland.at

Karel Malec

maleck@pef.czu.cz

Rainer Schmitl

1819001107@fh-burgenland.at

Jeta Sahatqija

sahatqija@pef.czu.cz

Sylvie Kobzev Kotásková

kotaskova@pef.czu.cz

Kamil Maitah

maitahk@pef.czu.cz

1 University of Applied Sciences in Eisenstadt, Eisenstadt, Austria

2 Czech University of Life Sciences Prague, Prague, Czech Republic that the behavioral differences stem from the deep link between oil and sugar prices. While oil did not influence the price of sugar during the outbreak of the financial crisis, it had tremendous influence on sugar prices during the outbreak of the corona crisis. Currently, sugar provides a substantial upside for an investor's portfolio since the demand and supply-side shock on oil prices due to corona crisis as well as the Saudi-Russian oil price war drove oil prices and consequently sugar prices to a historic low. Sugar futures provide the advantage of offering a smaller contract size compared to oil futures, and even though both commodities trade in contango as of March 2020, the sugar future curve is by far not as steep as the oils. Resultingly, investors benefit from lower rollover costs while prospering from a potential surge in oil prices.

Keywords Contango - Market crisis - Oil price dynamics . Portfolio diversification $\cdot$ Sugar prices

\section{Introduction}

The outbreak of the coronavirus in December 2019 in China and its subsequent dispersion across the globe has caused turmoil on the stock exchanges worldwide. The COVID-19 pandemic was accompanied by the fear of a global recession curtailing international GDPs. Among participants of the financial markets, the pandemic has manifested widespread concerns about the short-term and long-term impact on the economy as well as about a potential destabilization of financial markets due to decelerated growth rates and reluctant investments (Jana and Das 2020). This anxiety has triggered panic reactions, resulting in a bear market across global equity. 
When markets drop, investors search for alternatives which could provide a safe haven for their money or to protect their portfolios against devastating losses. This was evident during the outbreak of the financial crisis in 2007 and the consequent market shock, which has also sparked a tremendous decline in equity prices (Zhang et al. 2019). Investors have shifted their funds from equity to other asset classes, including commodities. Historically, this strategy proved to be successful since commodities have proven to be a safe haven and exhibited resilience in times of economic crises (Aziz et al. 2020; Baur and Lucey 2010).

The suggestion that commodity prices might provide diversification effects to an investor's portfolio in times of dropping equity markets is also supported by Gorton and Rouwenhorst (2019). The authors suggest using commodities as a means for equity portfolio diversification, as they found a negative relationship between commodity futures and equities. Alternative investments in times of dropping equity markets include the investment into gold and crude oil. Also, Raza et al. (2016) showed in their study that oil prices have a negative impact on the stock markets of all emerging economies, while the price of gold showed mixed results. The correlation between crude oil and US equities increases in crisis periods, while the correlation between gold and US equities become negative.

Both findings are supported by the behavior of gold and oil during the outbreak of the coronavirus crisis. While gold revealed negative correlation with equity markets during the outbreak of the pandemic, oil similarly dropped to a price of 20 USD per barrel. The demand shock was triggered by low economic activity due to the lockdown measurements of various countries around the globe, while the supply-side shock was caused by the trade war between Russia and Saudi Arabia (The Economist 2020). Since correlation patterns as well as market fundamentals and the degree of financialization are subject to change over time and within different market regimes, crude oil might currently pose a good investment opportunity.

Even though oil did not provide desired diversification effects during the outbreak of the COVID-19 pandemic, it performed well during the market turmoil caused by the financial crisis in 2008 . This can be justified by the fact that commodity prices are also subject to change based on market fundamentals. These physical market fundamentals, including inventories, weather events and diseases, matter (Covindassamy et al. 2017). During the financial crisis in 2008 when stocks fell, agricultural commodities offered a short-term alternative. This is mainly because the start of the global financial crisis in 2007-2008 overlapped with the upturn in the prices of agricultural commodities (Bohl et al. 2018). Stock prices started to decrease in November 2007, followed by agricultural commodities in July 2008. However, they generally remained well above the pre-2008 levels (Maitah and Smutka 2019). Tropical commodities including tea, cocoa, coffee, sugar and cotton bucked this trend.

Particularly, sugar was able to provide a good remedy for suffering equity portfolios, since it started a bullish trend in November 2007 which came to an end in January 2011, which was much later when compared to the other food staples (Covindassamy et al. 2017). This bullish trend in sugar was supported by the monetary policy enforced by the USA between 2005 and 2010; however, this effect vanished after 2011 (Fam et al. 2017). The aforementioned findings give rise to the question, whether sugar can provide an alternative investment to dropping equity prices during the crisis triggered by the coronavirus.

Investments into commodities are based on future contracts expiring within months or years. This fact can make the investment more expensive over time while having in mind also the cost of carry and storage (Robe and Wallen 2016; Ribeiro and Hodges 2005). The situation in April 2020 shows a huge contango on crude oil. While the May contract is tradeable for 22.74 USD, the July contract is currently valued at 29.66 USD. With increasing maturity, the contracts become even more expensive, with the October contract trading at 35.49 USD. This fact makes the crude oil much more expensive as the investor will roll over to the following contract months.

When cross-checking the contango on sugar, one can observe much lower values. The future is valued at 10.42 USD in May and 10.76 USD in October. When assessing longer maturities, it is observable that even for July 2021, the sugar future trades only at 11.30. Thus, sugar futures are considered to be an alternative investment for crude oil and equities as the contango is not as steep as in the case of oil futures. The Brent crude oil futures contract has a contango between May (K) and June (M) of 3610 USD, while the sugar contango for the two following contractsMay (K) and July (N), is only 89.6 USD.

Sugar is linked to crude oil due to ethanol production. For over three decades, sugar cane has been used for the production of ethanol. This is especially the case of Brazil, where most of the sugar cane mills produce sugar, ethanol and electricity (Lima et al. 2019; Dias et al. 2011). Efforts to meet increased demand for ethanol fuel in Brazil, but Salso all over the world are concentrated on building new plants and increasing acreage for sugar cane cultivation (Dias de Moraes et al. 2016; Soccol et al. 2010; Goldemberg and Guardabassi 2009). Besides the link between sugar and oil based on the ethanol production, also behaviorally both of the aforementioned can be associated with each other, especially in light of increasing financialization in the market (Gromb and Vayanos 2010). Pal and Mitra (2018) revealed a corroborative evidence for the positive interdependence between crude oil and the world 
food price index, comprising the sub-categories dairy, cereals, vegetable oil and sugar. The findings that there is a strong co-movement between sugar and oil are also supported by Serra (2011). Also, Silvennoinen and Thorp (2016) found positive correlation between crude oil, grains, oilseeds and sugar, which is largely consistent with the integration between oil and biofuel feedstocks. Hence, it might be beneficial for a trader to prefer trading sugar over oil, depending on the specific market situation.

Upon the comparison of both sugar and Brent future specifications, it can be observed that sugar offers various advantages over oil futures. These advantages include lower requirements for an investor's budget due to lower contract size. The contract size of sugar is $112,000 \mathrm{lb}$ trading at an average price of 0,165 USD per pound from 2006 to 2018, while the contract unit for oil is 1000 barrels, trading at an average price of 77.6 per barrel during the same time frame. Also, sugar offers lower volatility based on calculated historical volatility. While the average 50-day volatility in 2019 in sugar was about $24.9 \%$, in Brent it was at about $33.3 \%$ throughout the same time horizon. Additionally, also the margining is more beneficial for an investment into sugar futures as it is almost five times lower for sugar than for Brent crude oil, with sugar requiring 900 USD margin on average, compared to about 4300 USD margin on average for Brent. On the other hand, Brent crude oil offers higher liquidity (about 250.000 contracts traded in 2019 versus about 65,000 contracts traded in sugar) and more contracts. (Brent futures are available for every month, while sugar futures are only available per each quarter.)

According to Observatory of Economic Complexity (2017), raw sugar is the 119th most traded product. It is forecasted that during the upcoming decade, sugar exports will continue to remain concentrated, with Brazil keeping its leading position, accounting for $38 \%$ of the world trade (OECD-Food and Agriculture Organization 2019). With India's competitive positioning, the Asian market will experience a steady growth in production, thus accounting for $18 \%$ of the market share worldwide. An increase in production capacities is expected to be visible in the Australian market due to the investments in irrigation systems; as a result, a boost in export sales is expected. Sugar cane is considered a cash crop (Richardson 2009), and for some countries such as Brazil, it is closely linked to the economic development and wellbeing of the country (Dias de Moraes et al. 2015). Yet, according to Wilson (2010) these products are very vulnerable and volatile. This was also confirmed when agricultural commodity prices reached unprecedented heights in mid-2008, only then to collapse during the financial crisis (Adämmer and Bohl 2018; Dias de Moraes et al. 2016).
Research as well as practice confirms that the world market for sugar and sugar-containing products is constantly evolving (Smutka et al. 2011). Assuming normal weather conditions, according to OECD-Food and Agriculture Organization (2019), both sugar cane production and sugar beet production are projected to expand, mainly by remunerative returns and support policies on sugar cropbased ethanol production. The United States Department of Agriculture (2019) highlights that sugar consumption is projected to continue to increase due to the record use in India. Brazil and India are tied as top producers. On this note, Brazil's production is estimated to drop to 29.4 million tons considering that sugar cane is mainly being diverted toward ethanol production and toward sugar.

Since Gorton and Rouwenhorst (2019) proposed that commodities provide a good diversification effect for equity portfolios, the relationship between oil and equity as well as sugar and equity is examined. Hence, it is tested whether Brent crude oil futures would have provided a hedge option for equity investors during the period of 2006-2020. The following hypotheses were stated:

$H_{01} \quad$ Brent crude oil futures provided a good hedge option for equity investors for period 2006-2020.

$H_{02}$ Throughout the whole period of 2006-2020, Brent crude oil prices did not influence the price of sugar.

Raza et al. (2016) and Junttila et al. (2018) suggested that oil prices cannot provide a proper hedge against falling equity markets due to high correlation. The association between sugar and equity was tested during the outbreak of the financial crisis of 2007 as well as the outbreak of the coronavirus crisis in 2020. Thus, the $H_{03}$ and $H_{04}$ were stated.

$H_{03}$ Sugar provided a good hedge for equity investors during the financial crisis.

$H_{04}$ Sugar did not offer a safe haven for equity investors during the outbreak of the coronavirus crisis.

The observation suggested that while sugar provided good diversification effects during the crisis in 2007, it did not serve as a proper hedge during the coronavirus crisis. In order to investigate the reasons, the association between sugar and oil prices is tested according to the hypotheses $H_{05}$ and $H_{06}$.

$H_{05}$ Brent crude oil did not influence the sugar prices after the outbreak of the financial crisis.

$H_{06}$ Brent crude oil did not influence the sugar prices during the outbreak of the coronavirus crisis. 


\section{Materials and Methods}

The data consist of daily end-of-day prices using the S\&P 500 and the raw sugar future as well as the oil price. Within the paper, various time periods have been considered in order to test the association between oil, sugar and equity. Firstly, the co-movement between the three aforementioned has been tested for the overall time period from 2006 to 2020. Additionally, the time periods considered comprise the returns from October 9, 2006, to November 26, 2007, for the financial crisis (this period is called 2007 financial crisis in the paper) and the time period from February 12, 2019, to March 31, 2020, for the coronavirus crisis (this period is called COVID-19 in the paper). The time frames have been chosen according to the initiation of the beginning of each of the respective bear markets. The S\&P500 has reached a back-then all-time high on October 9, 2006, and declined subsequently, while the bear market of the coronavirus crisis has been initiated on February 12, 2020. The time horizon has been split into three subsets, whereby the first subset comprises the overall time frame and denotes the general co-movement of oil and sugar during the time horizon. The second subset comprises the 30 trading days preceding the outbreak of the respective market shock. It contributes to the analysis by analyzing whether a substantial co-movement or spillover effect has already prevailed immediately before the market shock triggered by both the financial crisis and the corona pandemic. The third subset comprises the data from October 10, 2007, to November 26, 2007, for the financial crisis and February 13, 2020-March 31, 2020, for the coronavirus crisis. The S\&P500 has reached an all-time high in the beginning of both periods. This point in time can be regarded as one of the most important for investors and in a portfolio management context, since the awareness of the transition from a bull to a bear market contributes to the overall portfolio performance. The time frame has been chosen in order to capture the initiation of the bear market, which is defined by a decline in asset prices of more than $20 \%$ from a recent high. Both time series have been retrieved from the Bloomberg database and represent the prices for ICE futures contracts.

The econometric approach is based on a linear regression model in which the returns of raw sugar futures are regressed against the returns of the S\&P 500. This method is commonly proposed by the literature in order to establish the association and co-movements between various asset classes including commodities. Studies employing a linear regression approach include Liu et al. (2018); Jeong (2017) and Ganapathyraman et al. (2018) among others.

The regression is performed for the period of 2006-2007, before and during the outbreak of the financial crisis as well was for the period 2019-2020 before and during the outbreak of the coronavirus crisis. Both market shocks have resulted in the initiation of a bear market, and the sugar price dynamics are explored and compared for both events. Specifically, the role of sugar as a hedge against falling equity prices should be analyzed immediately before and during the extreme market situation triggered by the outbreak of the financial crisis of 2007 and the coronavirus crisis in 2020. Consequently, the returns of raw sugar futures are as follows:

The returns of the price indices are calculated by using the log-returns, given by:

$\ln \left(\frac{p_{t}}{p_{t-1}}\right) 100$.

The multiple linear regression model was set up as proposed by Jana and Das (2020):

$R_{t}=\alpha+\beta_{1} S_{t}+\beta_{2}\left(S_{t} D_{1, t}\right)+\beta_{3}\left(S_{t} D_{2, t}\right)+e_{t}$

where $R_{t}$ is the return of the sugar future at time $t, \beta_{1}$ denotes the regression coefficient for a time period comprising the preceding 250 trading days before the market shock as well as the 30 days after the beginning of the equity bear market, $\beta_{2}$ denotes the regression coefficient testing the association 30 trading days before the beginning of the equity bear market, $\beta_{3}$ denotes the regression coefficient which tests the co-movement for a period of 30 trading days onset the outbreak of the equity bear market, $S_{t}$ denotes the return of the S\&P500 future at time $t$ and $D_{1}$ and $D_{2}$ denote dummy variables which are used in order to assign two sub-periods.

The variables can take the values of 1 and $0 . D_{1}$ takes the value of 1 for any $t$ that occurred shortly before (30 trading days) the market influence of the 2007 financial crisis and the coronavirus crisis, respectively, and 0 otherwise. Likewise, $D_{2}$ represents the crisis dummy, expressing the influence of both previously noted market turmoil after their respective occurrence (30 trading days after the initiation of a bear market from the recent high), taking the value of 1 after the initiation of both bear markets and remaining 0 for the preceding period.

The introduction of dummy variables is useful since the comparison is based on pre- and post-crisis periods, which is deemed to reveal the change in the market player's investment behavior. This approach was also supported by Baur and Lucey (2010) who accounted for asymmetries of positive and negative extreme shocks by assigning the value of 0 for stock and bond returns who fall into the $\mathrm{q} \%$ lower quantile.

A stylized fact which can be observed in financial markets is volatility clustering. While the linear regression is sufficient for serially correlated errors, it is incapable of including the stylized fact of volatility clustering which is 
often found in the residuals. In order to overcome this issue, a GARCH model is introduced in combination with the linear regression model (Ruppert and Matteson 2011). The issue of heteroskedasticity issue was also addressed by Capie et al. (2005) who assumed that the error term would exhibit conditional autoregressive heteroskedasticity. Since the linear regression model is a commonly used statistical tool for the analysis of a predictor as well as response variable, it is widely also applied on econometric data. Various empirical studies dealing with financial time series have shown that linear regression models are incapable of producing adequate results because residuals are usually heteroskedastic. While the ordinary least square estimates of the regression parameters are unbiased, the standard errors and subsequently the confidence intervals will be too narrow. By taking the heteroskedasticity into account, the variance estimator will be unbiased (Hossain and Ghahramani 2016).

Since the resulting error terms of the linear exhibited heteroskedasticity on the evaluation of the scatterplot, a GARCH $(1,1)$ was introduced. This use of a GARCHbased approach was supported by Forbes and Rigobon (2002) since adjustment for increased market volatility during a crisis period ensures that the changes in the relationship between two assets are not due to augmented market volatility. In this paper, the issue will be addressed by modeling the error term via a GARCH process of order $(1,1)$, which has been selected by using Akaike information criteria and is specified as follows:

$\sigma_{t}^{2}=\gamma+\delta_{1} e_{t-1}^{2}+\delta_{2} \sigma_{t-1}^{2}$

where $\sigma_{t}^{2}$ is the conditional variance of the current period, $e_{t-1}^{2}$ is the error term of the preceding period and $\sigma_{t-1}^{2}$ is the conditional variance of the preceding period.

Fitting the GARCH $(1,1)$ to the ordinary least square residuals, the conditional variances were determined. Consequently, the regressors of the linear regression were re-estimated by using weighted least squares, whereby the weights assigned were determined by using the reciprocals of the conditional variances as proposed by Capie et al. (2005). Ordinary least squares (OLSs) minimize the residual sum of squares in the form:

$\operatorname{RSS}(\beta)=\sum_{i=1}^{n}\left(y_{i}-\left(\left(x_{i} \beta\right)\right)^{2}\right.$

where $y_{i}$ denotes the dependent variable (the prices of sugar or oil) and $x_{i}$ denotes the independent variable (the prices of oil or equity).

It should be denoted that OLS is technically a special case of WLS, with all weights equal to 1 . Weighted least squares (WLSs) minimize the weighted sum of squares:
$\operatorname{WSS}\left(\beta, \vec{w}_{i}\right)=\sum_{i=1}^{n} w\left(y_{i}-\left(x_{i} \beta\right)\right)^{2}$

where $w$ denotes the weighting factor given by $\frac{1}{\sigma_{t}^{2}}, y_{i}$ denotes the dependent variable (the prices of sugar or oil) and $x_{i}$ denotes the independent variable (the prices of oil or equity).

Using the specified model, $b_{1}$ represents the association of raw sugar and the S\&P 500 throughout the whole period on average (250 trading days before and 30 days after the outbreak of the respective crisis) and $b_{2}$ signifies the relationship immediately (30 trading days) before the outburst of the respective crisis. Finally, $b_{3}$ characterizes the link between the sugar and equity returns onset the beginning of the bear market.

To make inferences about the obtained results, the definitions proposed by Baur and Lucey (2010) are introduced. A hedge can be defined as an asset that is negatively correlated or uncorrelated with another asset on average. While a diversifier is regarded as an asset exhibiting positive correlation with another asset on average, a safe haven displays negative or no correlation with another asset in times of market turmoil. Both the hedge and the diversifier do not necessarily have the property of reducing an occurring loss in times of crashing markets, since the correlation is a time-frame-dependent measure which only needs to hold on average.

\section{Results}

The associations between equity prices and the prices of Brent crude oil were tested, as well as between sugar and crude oil, which is given in Table 1.

The coefficient estimate $b_{1}$ signifies that the association between Brent and equity during the period between 2006 and 2020 was 0.3224 . This implies that there is positive association of Brent and equity prices. The coefficient estimate was highly significant, implying that we can reject the null hypothesis. From this, it follows that equity prices have influenced the Brent prices tremendously. Hence, Brent could not serve as a hedge for equity throughout the whole period.

The overall effect of Brent on sugar during the period from 2006 to 2020 is positive with a coefficient estimate $b_{1}$ of 0.183 . The coefficient is significant, and hence, we can reject the null hypothesis. This implies that there is positive connection between sugar prices and the prices of Brent. Thus, development of Brent prices has impacted the prices of sugar during the period of January 2006-March 2020.

By running the regression, it is assessed whether sugar would have provided a hedge at the onset of a crisis 
Table 1 Association of Brent versus equity and Brent versus sugar

\begin{tabular}{|c|c|c|c|c|c|c|}
\hline \multicolumn{4}{|c|}{ Brent versus equity } & \multicolumn{3}{|l|}{ Brent versus sugar } \\
\hline Equities & Coefficient estimates & SE & $t$-stat. & Coefficient estimates & SE & $t$-stat. \\
\hline$b_{1}$ & 0.32238502 & 0.0155307 & 20.7579185 & 0.183 & 0.016 & 11.377 \\
\hline$\gamma$ & 0.000 & 0.000 & 5.416 & 0.000 & 0.000 & 5.694 \\
\hline$\delta_{1}$ & 0.069 & 0.003 & 21.930 & 0.048 & 0.004 & 12.152 \\
\hline$\delta_{2}$ & 0.927 & 0.004 & 248.520 & 0.943 & 0.004 & 210.086 \\
\hline
\end{tabular}

triggering a market turmoil and causing dropping equity prices, represented in Table 2.

The results show that while sugar provided a good hedge during the outbreak of the financial crisis and the subsequent bear market in 2007 against falling equity markets, it did not provide a proper hedge or safe haven during the outbreak of the coronavirus crisis. This is due to the fact that the price of sugar is highly correlated with the oil price. While oil price was high during the outbreak of the financial crisis on August 9, 2007, it hit a low during the outbreak of the coronavirus crisis. Figure 1 shows the price developments of both the S\&P 500 as well as the sugar price development from 2006 to the end of 2007. While equity prices started to drop after the outbreak of the financial crisis in the fall of 2007, sugar maintained its price levels.

Currently, sugar provides a good investment opportunity since it is highly correlated with the oil price, which trades at a historic low due to the oil price war, while oil is only investable for investors with bigger funds due to the contract size, which is more than twice as high as the sugar future contract size. This makes sugar also available to smaller investors. Figure 2 shows the price development of both the S\&P 500 and the sugar price. Simultaneously, both prices started to decline sharply by the end of February 2020, during the global outbreak of the COVID pandemic.
Both arguments make it an attractive investment opportunity and could also act as a hedge for smaller investors and companies.

The coefficient estimate $b_{1}$, which signifies the average effect of stocks on sugar, is -0.0636 for the financial crisis. $b_{2}$ denotes the effect promptly before the crisis and is 0.0905 and $b_{3}$ (the coefficient measuring the effect during the crisis) is -0.0115 . All three coefficients are statistically insignificant, which implies that there was no influential spillover effect between sugar and equity. However, sugar served as a hedge for the entire period; the returns were negatively correlated with the equity returns on average. From this, it follows that in situations when stocks exhibited negative returns, sugar provided positive ones. Further, sugar can be regarded as a safe haven after the outbreak of the financial crisis, because $b_{3}$ also revealed negative association.

The average association between equity and sugar throughout the whole period is estimated by $b_{1}$ and is 0,0139 . With a value for $b_{2}$ of 0.0172 , the effect before the outbreak of COVID-19 is measured. The effect of sugar on equities after the upsurge of the pandemic and economic crisis, affecting equity markets and measured by $b_{3}$, is 0.0805. However, all three coefficients are statistically insignificant, indicating that the prices of equity did not influence the prices of sugar. Nonetheless, sugar served as a weak hedge during the overall period and before the outbreak of the crisis, since equity prices do not influence the prices of sugar.

Table 2 Association of sugar and equity prices during 2007 versus 2020

\begin{tabular}{|c|c|c|c|c|c|c|}
\hline \multicolumn{4}{|c|}{ 2007_Financial crisis } & \multicolumn{3}{|l|}{ 2020-COVID-19 } \\
\hline Equities & Coefficient estimates & SE & $t$-stat. & Coefficient estimates & SE & $t$-stat. \\
\hline$b_{1}$ & -0.063595513 & 0.075931459 & -0.837538402 & 0.013869181 & 0.071776651 & 0.193226911 \\
\hline$b_{2}$ & 0.090529354 & 0.067804949 & 1.335143765 & 0.017222312 & 0.062985328 & 0.73433714 \\
\hline$b_{3}$ & -0.011519004 & 0.067493924 & -0.170667271 & 0.080517577 & 0.067651161 & 1.190187658 \\
\hline$\gamma$ & 0.0000041122 & 0.0000020244 & 2.0313011927 & 0.0000052052 & 0.000001980 & 2.626470077 \\
\hline$\delta_{1}$ & 0.0762964899 & 0.0310414424 & 2.4578912597 & 0.409331934 & 0.075663645 & 5.409889167 \\
\hline$\delta_{1}$ & 0.8771326141 & 0.0507410613 & 17.2864459747 & 0.610536013 & 0.062473799 & 9.772672998 \\
\hline
\end{tabular}


Fig. 1 S\&P 500 versus sugar prices throughout 2006-2007
S\&P500 vs. Sugar Price Development 2007

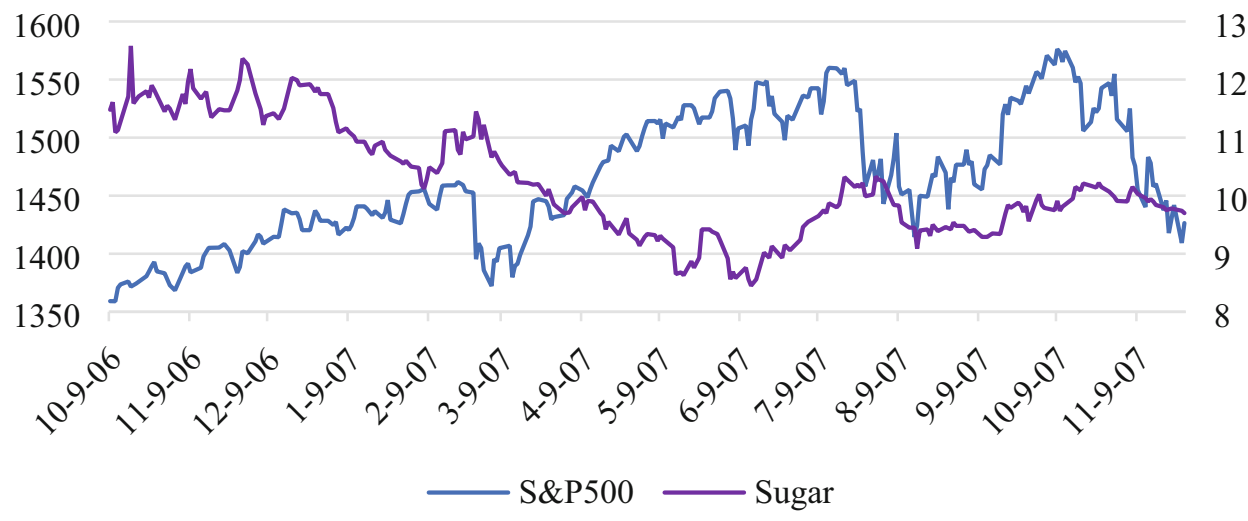

S\&P500 vs. Sugar Price Development 2019

Fig. 2 S\&P 500 versus sugar prices throughout 2019-2020

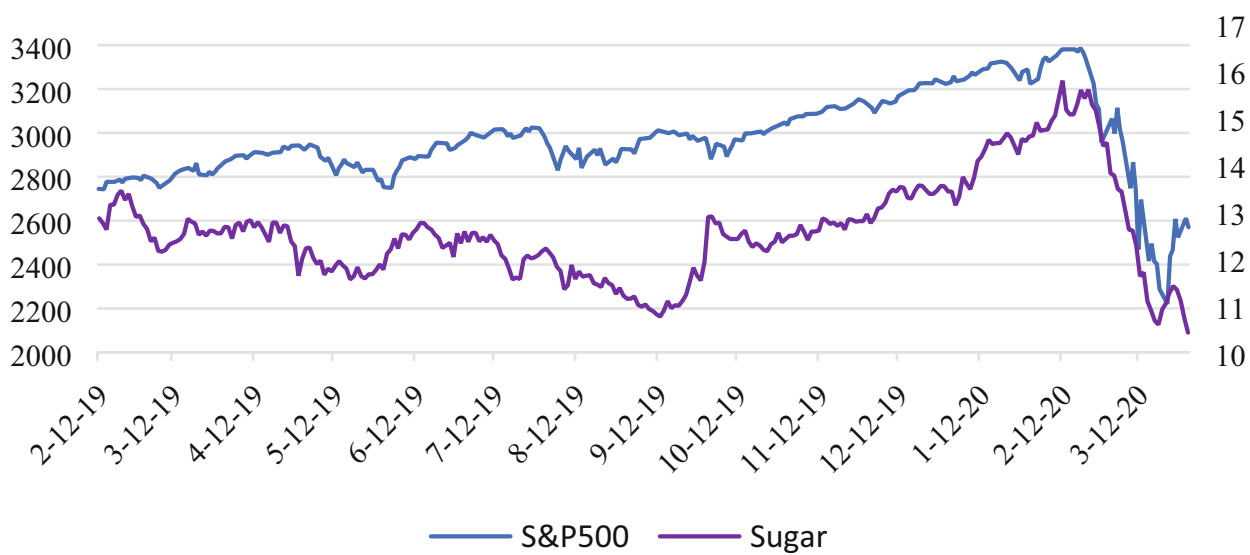

In order to justify and explain the above findings, the study elaborates on the connection between sugar and oil prices.

The overall effect of Brent crude oil on sugar prices is denoted by $b_{1}$. The total influence of Brent on sugar is 0.2358 . The coefficient is statistically significant at the $1 \%$ level. The null hypothesis can therefore be rejected, signifying that Brent crude oil influences the sugar price throughout the whole period. However, the coefficients $b_{2}$ and $b_{3}$, denoting the sub-period shortly before and immediately after the beginning of the bear market, were statistically insignificant. This means that Brent did not influence the sugar prices during these sub-periods.

The results for Brent are 0,1116 for $b_{1},-0,080228$ for $b_{2}$ and 0,1098 for $b_{3}$. While $b_{1}$ and $b_{3}$ were statistically significant, $b_{2}$ was insignificant. This implies that Brent prices were influencing the prices of sugar throughout the whole tested period. Further, it can be derived that Brent prices influenced the prices of sugar immediately after the market turmoil caused by the coronavirus crisis, since $b_{3}$ was significant at the $10 \%$ level. The null hypothesis can therefore be rejected for the periods $b_{1}$ and $b_{3}$.

The results of the association between sugar and Brent 2007 vs 2020 are given in Table 3.

Both arguments make it an attractive investment opportunity and could also act as a hedge for smaller investors and companies.

\section{Discussion}

Our findings show that sugar has served as a hedge against falling equity markets during the outbreak of the financial crisis in 2007, while it did not serve as a hedge against losses caused by the coronavirus in 2020 . In both cases, no statistically significant influence has been exerted from equity prices to sugar prices.

In order to elaborate on the reasons why sugar could not serve as a hedge against falling equity prices during the outbreak of the coronavirus crisis in 2020 , the association 
between sugar and oil prices is tested. Firstly, the regression for the overall time period from October 2006 to March 2020 shows that oil has influenced sugar prices significantly in the long run.

When testing association between sugar and oil prices from October 2006 (250 trading days preceding the outbreak of the crisis) to November 2007 (about 30 trading days into the bear market caused by the market shock), the regression coefficient $b_{1}$ is significant at the $1 \%$ level. From this, it follows that during this time period, oil has exerted a statistically significant influence on sugar prices.

Similarly, the co-movement of sugar and oil prices is tested for the period of February 2019-the end of March 2020. The time period comprises the 250 trading days preceding the market shock triggered by the coronavirus crisis as well as about 30 trading days into the bear market. The long-run coefficient $b_{1}$ shows that also in the case of the market shock caused by the coronavirus crisis oil has exerted influence on the sugar prices. The regression coefficient is significant at the $10 \%$ level.

Additionally, for both market shocks, the regression coefficient $b_{2}$ is derived. It indicates the co-movement of both oil and sugar immediately before, i.e., about 30 trading days the outbreak of the market turmoil due to the financial crisis and the coronavirus crisis. The regression coefficient determines whether an extraordinary influence of the oil price on the sugar price has already prevailed before the initiation of both bear markets. However, the coefficient $b_{2}$ is insignificant at the $10 \%$ level in both cases, which suggests that before the aforementioned market shocks, no significant influence of the oil price on the sugar price due to other extraordinary situations has existed.

Lastly, the regression coefficient $b_{3}$ is calculated. It denotes the association between oil and sugar prices throughout the first 30 trading days of the bear market caused by both the financial and the coronavirus crisis. For the financial crisis, this comprises a time horizon from October to November 2007, while for the coronavirus crisis, the time horizon comprises February and March
2020. The results show that while $b_{3}$ was statistically insignificant during the financial crisis, it was significant during the market shock caused by the coronavirus crisis. This reveals that oil has not exerted influence on the prices of sugar during the financial crisis but has influenced the prices of sugar significantly during the outbreak of the coronavirus crisis.

The aforenoted explains why sugar was able to serve as a hedge against losses arising from declining equity markets, while it has not been able to do so during the coronavirus crisis. An oil price war was triggered on March 6, 2020, during a meeting of the Organization of the Petroleum Exporting Countries (OPEC) in Vienna, where Russia refused to slash production. Saudi Arabia retaliated by offering discounts to buyers and the promise of pumping more crude oil. Specifically, the Saudis promised ramp up oil production to provide customers with 12.3 million barrels per day in April 2020, about 25\% more than March 2020. Russia intensified their position in turn and raised output as well. On March 9, 2020, the oil prices plummeted by $24 \%$, which posed the steepest one-day loss in almost 30 years (The Economist 2020). Tremendously dropping oil prices, having statistically significant influences on the prices of sugar made prices of sugar drop alike oil. During the same time period, also equity markets were dropping enormously and hence sugar could not provide diversification benefits for an investor's portfolio.

The findings of our study are supported by various other studies, including Junttila et al. (2018) who also confirmed the change in correlation between sugar and crude oil from 2008 to 2020. Basak and Pavlova (2016) support our results as well and argue that enhanced financial speculation within commodity markets as well as increased overall financialization of the market poses a trigger for a change in correlation. Increased correlation diminishes potential diversification benefits arising from the inclusion of soft commodities in an investor's portfolio. With Brent crude oil having close links to the price of sugar, both instruments cannot serve as a hedge for one another. This finding

Table 3 Association of sugar and Brent prices 2007 versus 2020

\begin{tabular}{|c|c|c|c|c|c|c|}
\hline \multicolumn{4}{|c|}{ 2007-sugar-Brent } & \multicolumn{3}{|l|}{ 2020-sugar-Brent } \\
\hline Equities & Coefficient estimates & SE & $t$-stat. & Coefficient estimates & SE & $t$-stat. \\
\hline$b_{1}$ & 0.235787747 & 0.064747799 & 3.641633399 & 0.111563796 & 0.072342794 & 1.870600 \\
\hline$b_{2}$ & -0.003317903 & 0.061291785 & -0.054132912 & -0.080228 & 0.062351649 & -0.650793 \\
\hline \multirow[t]{2}{*}{$b_{3}$} & -0.048686633 & 0.060801829 & -0.800742905 & 0.109788847 & 0.068307409 & 1.670275812 \\
\hline & 0.00000345704 & $2.37963 \mathrm{E}-06$ & 1.452760611 & 0.000011757 & 0.00000388595 & 3.025525504 \\
\hline$\delta_{1}$ & 0.138634647 & 0.067272563 & 2.060790314 & 0.263869556 & 0.026360897 & 10.00988544 \\
\hline$\delta_{2}$ & 0.766811257 & 0.115522919 & 6.637741379 & 0.67532149 & 0.054860719 & 12.30974547 \\
\hline
\end{tabular}


can be justified by the fact that increased activity of financial institutions in commodity trading enhances the correlation between oil and commodity prices (Büyüksahin et al. 2010; Cheng et al. 2012; Bruno et al. 2017).

Our findings are also supported by Esmaeili and Shokoohi (2011), who suggest that crude oil influences the price of sugar over a long-term perspective. This is driven by the fact that oil-exporting regions have been growing due to the growth of demand in China. With increased oil prices, there is a bigger incentive to use food crops for the production of biofuel energy. This, in turn, makes sugar prices rise. Also, the results of Zhang et al. (2010) support the close relation between oil and sugar prices. Also, Morana (2013) showed that during market turmoil, an increase in the correlation between oil prices and the stock market increases.

Another reason why sugar underperformed upon the outbreak of the coronavirus crisis poses the fact that the outbreak of diseases harms sugar production and hence the price dynamics are substantially affected. In this regard, Covindassamy et al. (2017) show that price dynamics of sugar are not just determined by its correlation or comovement with other asset classes but are also subject to change based on physical market fundamentals. The output of soft commodities is influenced by planting decisions, disease epidemics and weather conditions such as temperature and rain. Particularly, diseases and weather changes are the main sources of exogenous shocks in soft markets, which appear with high frequency. Extreme temperatures and scarcity of water as well as the outbreak of diseases deteriorate the sugar market overall. On the financial side, Covindassamy et al. (2017) show that the comovement between equity and commodity markets depends on the overall market sentiment within equity markets as well as the intensity of financial speculation in commodity futures market.

The overall sugar market and its dynamics are, however, influenced not only by market fundamentals, but also by regulations. In various countries, sugar is considered as a strategic commodity. From this, it follows that the sugar market is regulated in an attempt to be self-sufficient with regard to the production of sugar (Slaboch and Kotyza 2016). For example, in Russia, the government heavily supports the growth of the sugar industry by using direct as well as indirect measures. Upon the entry of Russia into the WTO, sugar has been protected by denoting it as a sensitive item with limited to no liberalization. This supports the argument that regulations with regard to sugar production and hence the price dynamics are also to be considered (Smutka et al. 2014). In this regard, it should be denoted that there is also a link between sugar and oil due to the ethanol production. The aforenoted also contributes to the changes in the sugar price (Lima et al. 2019; Dias et al. 2011; Dias de Moraes et al. 2016).

Another factor, which influences the prices of commodities, heavily influences the degree of financialization. Financial speculation and enhanced financialization lead to an increased correlation between equity and commodity markets (Gromb and Vayanos 2010; Büyükşahin et al. 2010). However, the correlation between commodity and equity markets is not just subject to changes in financialization but is also influenced by physical market fundamentals such as weather and other events causing exogenous shocks. Ji (2012) showed that original price and volatility mechanisms with regard to the commodity market vanished during the 2008 financial crisis. Before the crisis, the main driver of the oil price was pure speculation. After the 2008 meltdown, the crude oil price was heavily influenced by the stock market as well as the foreign exchange market, with the US dollar index being the main factor driving the oil price in the long as well as the short run.

Additionally, the financial crisis has changed not only the correlation and co-movement between the equity and the oil market, but also the volatility effects within the overall commodity prices. Sierra et al. (2018) showed in their study that there is a transmission of the volatility from the stock market to commodity prices. The enhanced volatility pre- and post-crisis year of 2008 of the S\&P 500 index spilled over to volatility of commodity prices. Particularly, coffee, sugar and soy were affected by the enhanced volatility. Also, evidence was found for the leverage effects of corn, coffee, wheat and cocoa. This implies that negative shocks have a greater impact than positive shocks on the aforementioned markets. Between 2011 and 2016, the volatility transmission continued, especially with regard to the sugar and soy market. No evidence was found that would prove leverage in the sugar market. Even though volatility transmission takes place from and between other asset classes including sugar, the overall volatility in sugar futures remains low. This can be attributed to overall lower liquidity in sugar markets compared to oil markets. Studies, which support the aforementioned, include Kalimipalli and Nayak (2012). Also, Liao et al. (2008) show that enhanced trading volume comes at the price of higher volatility. This supports trading sugar futures over oil futures since they provide the advantage of offering lower volatility.

According to Halkos and Tsirivis (2019), hedging via futures in the commodity market can be very useful as they allow for simple handling. Nonetheless, trading futures is accompanied by some risks and discomfort. Usually, counterparties close out on their positions prior to maturity, which implies that physical delivery is rarely taking place since both parties exploit the price fluctuations when they 
are in their favor. This speculation attracts investors whose purpose is not to hedge the oil output, but rather make profit stemming from the price movements of energy commodities. In order to predict cane derivatives prices of sugar, Silva et al. (2019) propose the use of extreme learning machines.

A major benefit of trading sugar futures instead of oil futures is posed by the lower contract size. While a May 2020 future in oil was only tradable for approximately 30.000 USD, a sugar future was tradable at roughly 11,500 USD. The lower contract value of raw sugar makes it more suitable for small to mid-sized companies because lower cash-flows are required in order to meet the cash obligation.

For investors, the contango makes speculation on crude oil prices very expensive due to higher rollover costs. The contango on oil futures is far worse than the contango on sugar. While March 2021 oil futures trade about 70\% higher compared to May 2020 oil futures, trading longdated sugar futures demands only a premium of $10 \%$. Oil prices are currently trading at a historical low and hence might pose a good speculation opportunity.

\section{Conclusion}

The occurrence of the coronavirus in December 2019 in China was convoyed by immense damage measured by the number of deaths and economic costs. Further, the COVID19 pandemic was accompanied by the rising fear of economic drawbacks curtailing global GDPs. This anxiety triggered panic reactions, resulting in a bear market on global equity markets. A similar reaction of market participants was observable during the outbreak of the financial crisis in 2007/2008. When equity markets drop, investors seek for protection of their portfolios against devastating losses. Historically, commodities have proven to be a safe haven and exhibited resilience in times of economic crises.

The goal of this paper was to elaborate on why sugar served as a hedge against falling equity markets during the outbreak of the financial crisis in 2007, while it did not serve as a hedge during the outbreak of the COVID-19 pandemic. Both events have caused a tremendous shock on equity markets and triggered turmoil on the aforementioned. In order to elaborate on the different sugar price dynamics, the econometric approach is based on a multiple linear regression approach. A GARCH $(1,1)$ was fit to the ordinary least square residuals in order to account for enhanced volatility and volatility clustering during times of market crashes. Consequently, the association between equity, oil and sugar prices was tested.
The results suggest that sugar has served as a hedge against falling equity markets during the outbreak of the financial crisis in 2007, while it did not serve as a hedge against devastating losses caused by the coronavirus in 2020. In both cases, no statistically significant influence has been exerted from equity prices to sugar prices. Upon the analysis for why the sugar price dynamics have shown different behavior during both market turmoil, the association between sugar and oil is tested. The results show that there is a long-term co-movement between sugar and oil prices, as well as equity and oil prices, calculated for the 14-year time horizon from 2006 to 2020 . A statistically significant co-movement between oil and sugar was also found for the time period comprising the trading year succeeding both the bear market caused by the financial crisis and the coronavirus crisis. Further, oil has not exerted statistically significance on sugar price during the 30 trading days preceding both market shocks. This was important in order to determine whether a statistical influence has already prevailed before both market crashes, which cannot be attributed to the financial or the coronavirus crisis. Lastly, the results indicate that oil has not exerted influence on the prices of sugar during the first 30 trading days of the financial crisis but has influenced the prices of sugar significantly during the outbreak of the coronavirus crisis.

The difference in influence of oil price on the sugar prices on the initiation of both bear markets explains the differences in the dynamics of the sugar price. In March 2020, oil was hit by a double shock on both the demand and supply side. The double shock on oil was caused by falling demand due to the lockdowns declared by most countries due to the coronavirus, while the supply-side shock was caused by the oil price war between Russia and Saudi Arabia. The respective prices show that while oil traded at around 99 USD in November 2007, oil prices have written history by turning negative in April 2020. With oil prices trading at a historical low, while exerting a great influence on the prices of sugar, the price of sugar dropped alike the oil price.

Even though the results show that sugar could not serve as a hedge during the outbreak of the COVID-19 market crash due to its high correlation with oil, it currently provides an attractive investment opportunity. Sugar futures might not be as liquid as oil futures, yet the lower contract size in sugar allows a wider range of companies to participate in the futures trading. Further, realized volatility in sugar was historically way smaller than the realized volatility in oil. However, the strongest argument for preferring sugar futures over oil futures stems from the fact that the contango on oil is currently trading way higher than the contango on sugar futures. A lower contango enables investors to roll over their position at lower costs. 
In order to profit from rising oil prices in the future, sugar might be an alternative choice providing the same upside with regard to price increases but delivering several advantages over the investment into oil futures simultaneously.

Future works could focus on the exploration of nonlinear relationships between the oil, equity and sugar price in order to derive more insights regarding the co-movement and spillover effects of the aforementioned.

Author Contribution JB, KM and MM conceived and designed the research; JB, RS and KM run the model and analyzed the obtained results; JS and SK-K contribute to the introduction, discussion and final form of the paper.

\section{Compliance with Ethical Standards}

Conflict of interest The authors declare no conflict of interest.

\section{References}

Adämmer, P., and M.T. Bohl. 2018. Price discovery dynamics in European agricultural markets. Journal of Futures Markets 38(5): 549-562.

Aziz, T., R. Sadhwani, U. Habibah, and M.A.A.I. Janabi. 2020. Volatility spillover among equity and commodity markets. Sage Open 10: 1-7.

Basak, S., and A. Pavlova. 2016. A model of financialization of commodities. The Journal of Finance 71(4): 1511-1556.

Baur, D.G., and B.M. Lucey. 2010. Is gold a hedge or a safe heaven? An analysis of stocks, bonds and gold. The Financial Review 45: 217-229.

Bohl, M.T., P.L. Siklos, and C. Wellenreuther. 2018. Speculative activity and returns volatility of Chinese agricultural commodity futures. Journal of Asian Economics 54: 69-91.

Bruno, V.G., B. Büyüksahin, and M.A. Robe. 2017. The financialization of food? American Journal of Agricultural Economics 99(1): 243-264.

Büyüksahin, B., M.S. Haigh, and M.A. Robe. 2010. Commodities and equities: Ever a "Market of One"? The Journal of Alternative Investments 12(3): 76-95.

Capie, F., T.C. Mills, and G. Wood. 2005. Gold as a hedge against the dollar. Journal of International Financial Markets, Institutions and Money 15(4): 343-352.

Covindassamy, G., M.A. Robe, and J. Wallen. 2017. Sugar with you coffee? Fundamentals, financials, and softs price uncertainty. Journal of Future Markets 37(8): 744-765.

Dias de Moraes, M.A.F., F.C. Ribeiro de Oliveira, and R.A. DiazChavez. 2015. Socio-economic impacts of Brazilian sugar cane industry. Environmental Development 16: 31-43.

Dias de Moraes, M.A.F., M.R.P. Bacchi, and C.E. Caldarelli. 2016. Accelerated growth of the sugarcane, sugar, and ethanol sectors in Brazil (2000-2008): Effects on municipal gross domestic product per capita in the south-central region. Biomass and Bioenergy 91: 116-125.

Dias, M.O.S., M.P. Cunha, C.D.F. Jesus, G.J.M. Rocha, J.G.C. Pradella, C.E.V. Rossell, R.M. Filho, and A. Bonomi. 2011. Second generation ethanol in Brazil: Can it compete with electricity production? Bioresource Technology 102(19): 8964-8971.
Esmaeili, A., and Z. Shokoohi. 2011. Assessing the effect of oil price on world food prices: Application of principal component analysis. Energy Policy 39(2): 1022-1025.

Fam, P.G., R. Hennani, and N. Huchet. 2017. US monetary policy, commodity prices and the financialization hypothesis. Review of Economic and Business Studies 10(2): 53-77.

Forbes, K.J., and R. Rigobon. 2002. No contagion, only interdependence: measuring stock market comovements. The Journal of Finance 57(5): 2223-2261.

Ganapathyraman, S., S. Sugumaran, T. Komatheswari, S.T. Surulivel, S. Selvabaskar, V.V. Anad, and V. Rengarajan. 2018. A study on relationship between price of us dollar and selected commodities. International Journal of Pure and Applied Mathematics 119(15): 203-224.

Goldemberg, J., and P. Guardabassi. 2009. Are biofuels a feasible option?. Energy Policy 37(1): 10-14.

Gorton, G., and K.G. Rouwenhorst. 2019. Facts and fantasies about commodity futures. Financial Analysts Journal 62(2): 47-68.

Gromb, D., and D. Vayanos. 2010. Limits of arbitrage: The state of the theory. The National Bureau of Economic Research 2: 251-275.

Halkos, G.E., and A.S. Tsirivis. 2019. Energy commodities: A review of optimal hedging strategies. Energies 12(20): 3979.

Hossain, S., and M. Ghahramani. 2016. Shrinkage estimation of linear regression models with GARCH errors. Journal of Statistical Theory and Applications 15(4): 405-423.

Cheng, I.A., A. Kirilenko, and W. Xiong. 2012. Convective risk glows in commodity futures markets. The National Bureau of Economic Research 19(5): 1733-1781.

Jana, R. K., and D. Das. 2020. Did bitcoin act as an antidote to the Chinese equity market and booster to altcoins during the novel Coronavirus outbreak?. SSRN. https://doi.org/10.2139/ssrn.3544794.

Jeong, K. 2017. Causal relationships in moments between agricultural commodity prices and crude oil prices. Korean Journal of Agricultural Management and Policy 44(1): 60-76.

$\mathrm{Ji}$, Q. 2012. System analysis approach for the identification of factors driving crude oil prices. Computers \& Industrial Engineering 63: 615-625.

Junttila, J., J. Pesonen, and J. Raatikainen. 2018. Commodity market based hedging against stock market risk in times of financial crisis: The case of crude oil and gold. Journal of International Financial Markets, Institutions and Money 56(C): 255-280.

Kalimipalli, M., and S. Nayak. 2012. Idiosyncratic volatility vs. liquidity? Evidence from the US corporate bond market. Journal of Financial Intermediation 21(2): 217-242.

Liao, H.C., Y.H. Lee, and Y.B. Suen. 2008. Electronic trading system and returns volatility in the oil futures market. Energy Economics 30(5): 2636-2644.

Lima, C.R.A., G. Rivas de Melo, B. Stosic, and T. Stosic. 2019. Cross-correlations between Brazilian biofuel and food market: Ethanol versus sugar. Physica A Statistical Mechanics and its Applications 513: 687-693.

Liu, J., Y. Tian, and Q. Yan. 2018. Modelling and forecasting of commodity trading price. Journal of Physics Conference Series 1060: $1-6$

Maitah, M., and L. Smutka. 2019. The development of world sugar prices. Sugar Tech 21: 1-8.

Morana, C. 2013. Oil price dynamics, macro-finance interactions and the role of financial speculation. Journal of Banking \& Finance 37(1): 206-226.

OEC. 2017. Raw Sugar. Observatory of Economic Complexity. https://oec.world/en/profile/hs92/41701/. Accessed 7 April 2020.

OECD-FAO. 2019. Agricultural Outlook 2019-2028: Food and Agriculture Organization of the United Nations. 
https://doi.org/10.1787/agr_outlook-2019-en. Accessed 5 April 2020.

Pal, D., and S.K. Mitra. 2018. Interdependence between crude oil and world food prices: A detrended cross correlation analysis. Physica A: Statistical Mechanics and its Applications 492: 1032-1044.

Raza, N., S.J.H. Shahzad, A.K. Tiwari, and M. Shhbaz. 2016. Asymmetric impact of gold, oil prices and their volatilities on stock prices of emerging markets. Resources Policy 49(C): 290-301.

Ribeiro, D.R., and S.D. Hodges. 2005. A contango-constrained model for storable commodity prices. Journal of Future Markets 25(11): $1025-1044$.

Richardson, B. 2009. Restructuring the EU-ACP sugar regime: Out of the strong there came forth sweetness. Review of International Political Economy 16(4): 673-697.

Robe, M.A., and J. Wallen. 2016. Fundamentals, derivatives market information and oil price volatility. Journal of Futures Markets 36(4): 317-344.

Ruppert, D., and D.S. Matteson. 2011. Statistics and data analysis for financial engineering. New York: Springer-Verlag.

Serra, T. 2011. Volatility spillovers between food and energy markets: A semiparametric approach. Energy Economics 33(6): $1155-1164$.

Sierra, L.P., L.E. Giron, V. Giron, and A. Giron. 2018. What is the spillover effect of the U.S Equity and money market on the key Latin American agricultural exports? Global Economy Journal 18(4): $1-9$.

Silva, N., I. Siqueira, S. Okida, S.L. Stevan Junior, and H. Siqueira. 2019. Neural networks for predicting prices of sugarcane derivatives. Sugar Tech 21(3): 514-523.

Silvennoinen, A., and S. Thorp. 2016. Crude oil and agricultural futures: An analysis of correlation dynamics. Journal of Futures Markets 36(6): 522-544.

Slaboch, J., and P. Kotyza. 2016. Comparison of self-sufficiency of selected types of meat in the Visegrad countries. Journal of Central European Agriculture 17(3): 793-814.
Smutka, L., I. Pokorna, and J. Pulkrabek. 2011. The World Production of Sugar. Listy Cukrovarnické a Repařské 127(3): 78-82.

Smutka, L., M. Maitah, and E.A. Zhuravleva. 2014. The Russian Federation-specifics of the sugar market. Agris on-line Papers in Economics and Informatics 6(1): 73-86.

Soccol, C.R., L.P.S. Vandenberghe, A.B.P. Medeiros, S.G. Karp, M. Buckeridge, L.P. Ramos, A.P. Pitarelo, V. Ferreire-Leitao, L.M.F. Gottschalk, M.A. Ferrara, E.P.S. Bon, L.M.P. Moraes, J.A. Araujo, and F.A.G. Torres. 2010. Bioethanol from lignocelluloses: Status and perspectives in Brazil. Bioresource Technology 101(13): 4820-4825.

The Economist. 2020. No one is likely to win the oil-price war. The Economist.

https://www.economist.com/finance-and-economics/2020/03/12/ no-one-is-likely-to-win-the-oil-price-war. Accessed 10 April 2020.

USDA. 2019. Sugar: World Markets and Trade. USDA Foreign Agricultural

Service. https://apps.fas.usda.gov/psdonline/circulars/Sugar.pdf. Accessed 7 April 2020.

Wilson, B.R. 2010. Indebted to fair trade? Coffee and crisis in Nicaragua. Geoforum 41(1): 84-92.

Zhang, Q., S. Hu, L. Chen, R. Lin, W. Zhang, and R. Shi. 2019. A new investor sentiment index model and its application in stock price prediction and systematic risk estimation of bull and bear market. International Journal of Finance and Banking Research 5(1): $1-8$.

Zhang, Z., L. Lohr, C. Escalante, and M. Wetzstein. 2010. Food versus fuel: what do prices tell us? Energy Policy 38(1): $445-451$.

Publisher's Note Springer Nature remains neutral with regard to jurisdictional claims in published maps and institutional affiliations. 